\title{
The response of the tremor of patients with Parkinsonism to peripheral nerve stimulation
}

\author{
ROBERT J. MONES AND ARTHUR H. WEISS
}

\author{
From the Neurology Department, Mount Sinai Medical School, New York, \\ New York, U.S.A.
}

The involuntary tremors seen in patients with Parkinson's disease remain a poorly understood phenomenon. Tremors are thought by many observers to be generated in the basal-gangliathalamic structures and then transmitted to the anterior horn cells via the spinal cord (Jasper and Bertrand, 1966). The cessation of the tremor after lesions are made in the globus pallidus or ventral thalamus would support this theory (Markham and Rand, 1963), as would the observation that individual cells in the ventral thalamus can be shown to fire synchronously with the spontaneous tremor seen in the contralateral limb (Cordeau, Gybels, Jasper, and Poirier, 1960; Lamarre and Cordeau, 1963; Jasper and Bertrand, 1966). Other investigators have emphasized the role of the spinal cord in generating the tremor (Jung, 1941). The clinical observation that the tremor rate in the hand and foot in an individual patient can be independent of each other would suggest that more peripheral structures are in control of the tremor. Aronson (1966) has considered the possibility that the tremor is the result of upsetting the delicate balance of control of the motor system, which implicates the sensory system, reticular apparatus, cerebrum, cerebellum, the basal ganglia, and thalamic structures.

\section{METHODS}

Five patients with Parkinson's disease and a gross resting tremor were studied. Continuous electromyographic recordings were made of the activity in the right and the left extensor digitorum longus muscle by means of coaxial electromyographic needles inserted into the belly of the muscle. The electrical activity of the muscle was recorded on a cathode ray oscillograph and many $2 \mathrm{sec}$ periods, taken at random, were photographed for analysis. Random single $0.5 \mathrm{msec}$ duration, square wave, supra maximal stimulation was given to ipsilateral or contralateral median or ulnar nerve at the wrist. The nerve stimulation was given during the first $200 \mathrm{msec}$ of the $2 \mathrm{sec}$ period photographed, so that the immediate effect of the nerve stimulation could be photographed and analysed.

The $2 \mathrm{sec}$ periods were thus divided into: $(a)$ control tremor period, $(b)$ experimental periods which contained a supra maximal nerve stimulation. The effect of the nerve stimulation was studied by measuring the intervals between the centres of each tremor burst and noting the number of motor units firing and the maximum voltage of the motor units. Thus for each extensor digitorum muscle tremor studied, five different categories of $2 \mathrm{sec}$ periods were photographed and analysed. At least 20,2 sec periods were analysed in each of these categories:

A. Control tremor of extensor digitorum longus muscle.

B. Tremor after ipsilateral median nerve stimulation.

C. Tremor after ipsilateral ulnar nerve stimulation.

D. Tremor after contralateral median nerve stimula tion.

E. Tremor after contralateral ulnar nerve stimulation.

The intervals between each tremor burst were first measured and analysed. Templates of the control tremor were made and then compared with the experimental period. The tremor intervals in each $2 \mathrm{sec}$ control period were remarkably regular and, therefore, after measuring the first two tremor bursts, the subsequent tremor bursts could be accurately predicted. Thus we could determine if the nerve stimulation experiments changed the tremor and whether the reasserted regular tremor occurring after the nerve stimulation was or was not in phase with the prestimulation bursts. The 'predicted tremor pattern' is therefore that exact tremor pattern expected had not nerve stimulation been given.

\section{RESULTS}

Each patient had the tremor in the right and the left extensor digitorum longus muscle studied as described in the method. Five patients were studied. The result of the experimental $2 \mathrm{sec}$ period could be divided as follows: The post-stimulation tremor interval revealed:

A. No change from the control tremor.

B. A change in the tremor burst intervals and a concomitant change in the "predicted tremor 
INTERVAL OF

BURSTS IN msec.
CONTROL BURST

(No Nerve Stimulation)
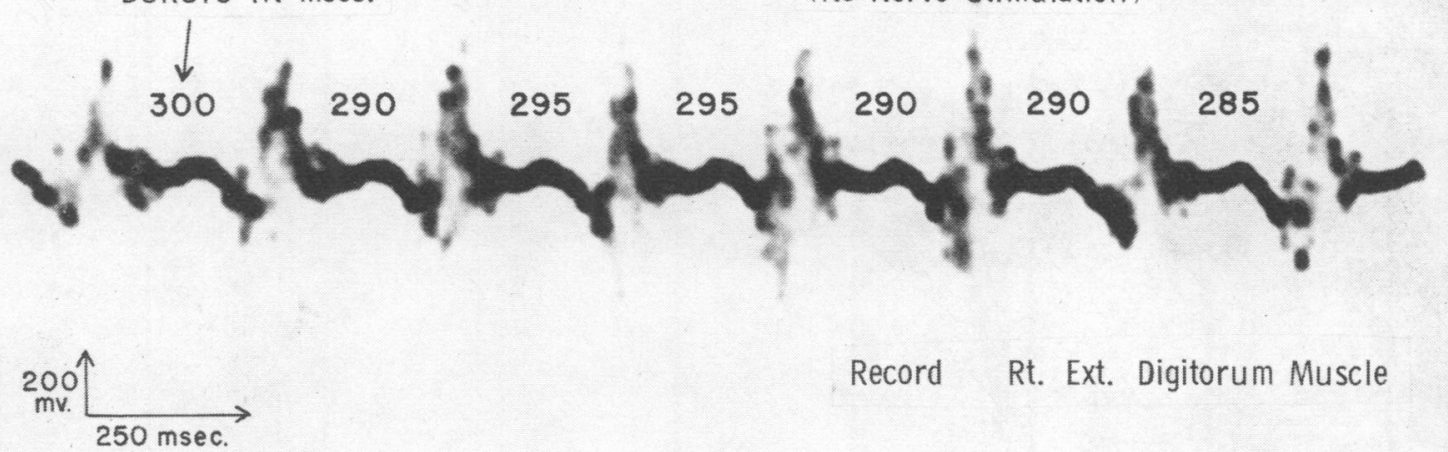

Record Rt. Ext. Digitorum Muscle

FIG. 1. Regularity of the tremor burst in the 2 sec period. The amplitude of the motor units and the number of motor units making up each tremor burst is similar. The maximum difference between these intervals in this 2 sec period is $3 \%$. The intervals are measured in milliseconds from the centre of each tremor burst to the next.

pattern' (out of phase with the prestimulation bursts).

C. A change in the tremor burst intervals with a subsequent return to the predicted tremor pattern' (in phase with the prestimulation bursts).

The control pattern in all cases revealed a remarkably constant tremor pattern in the $2 \mathrm{sec}$ period analysed (Fig. 1). The intervals varied less than $6 \%$ within the short $2 \mathrm{sec}$ periods. Changes in the spontaneous tremor bursts varied as much as $30 \%$ in the same muscle when the tremor was measured 15 to 20 minutes later. The changes in the tremor intervals which occurred without nerve stimulation occurred gradually and were not a significant problem when short periods - that is, 2 sec periodswere analysed.

The random ipsilateral stimulation of the ulnar or median nerves at the wrist had a dramatic effect on the tremor burst patterns seen in the extensor digitorum longus muscle (Figs. $2 \mathrm{a}$ and $\mathrm{b}$ ). The change in tremor pattern was predictable and occurred in over $75 \%$ of the 2 sec period recordings containing the random nerve stimulation. The most common change in the tremor was a decrease in the tremor interval and a subsequent change in the predicted tremor pattern. The post-stimulation tremor bursts were thus out of phase with the pre-stimulation tremor bursts and thus the pattern of the tremor appeared to be 'reset' by the peripheral nerve stimulation.

The shortened interval increased gradually on subsequent spontaneous tremor bursts and returned to the control value after three or four bursts which represented in total 750 to $1,000 \mathrm{msec}$. The exact portion of the tremor cycle in which the electrical stimulation occurred at the wrist did not appear to be critical. The stimulation occurred at random and was observed before a burst, after a burst, and sometimes during a burst. In all these circumstances a decrease in the subsequent tremor interval was a consistent finding in all patients. There was no difference in the response of the tremor pattern of the extensor digitorum muscle when either the ulnar or median nerve was stimulated (Figs. 2a and b).

Contralateral nerve stimulation induced equivocal changes in the post-stimulation bursts (Fig. 3). Seventy per cent of the contralateral experiments did not reveal any change in the post-stimulation tremor whereas $30 \%$ showed minimal changes of up to $5 \%$ when 20 sweeps were averaged (see Fig. 4).

In order to define more clearly the observed changes, 20 consecutive $2 \mathrm{sec}$ periods were averaged in each category for the tremor in one muscle (Fig. 4, Table I).

The tremor interval immediately preceding the stimulation was considered interval -1 . The 


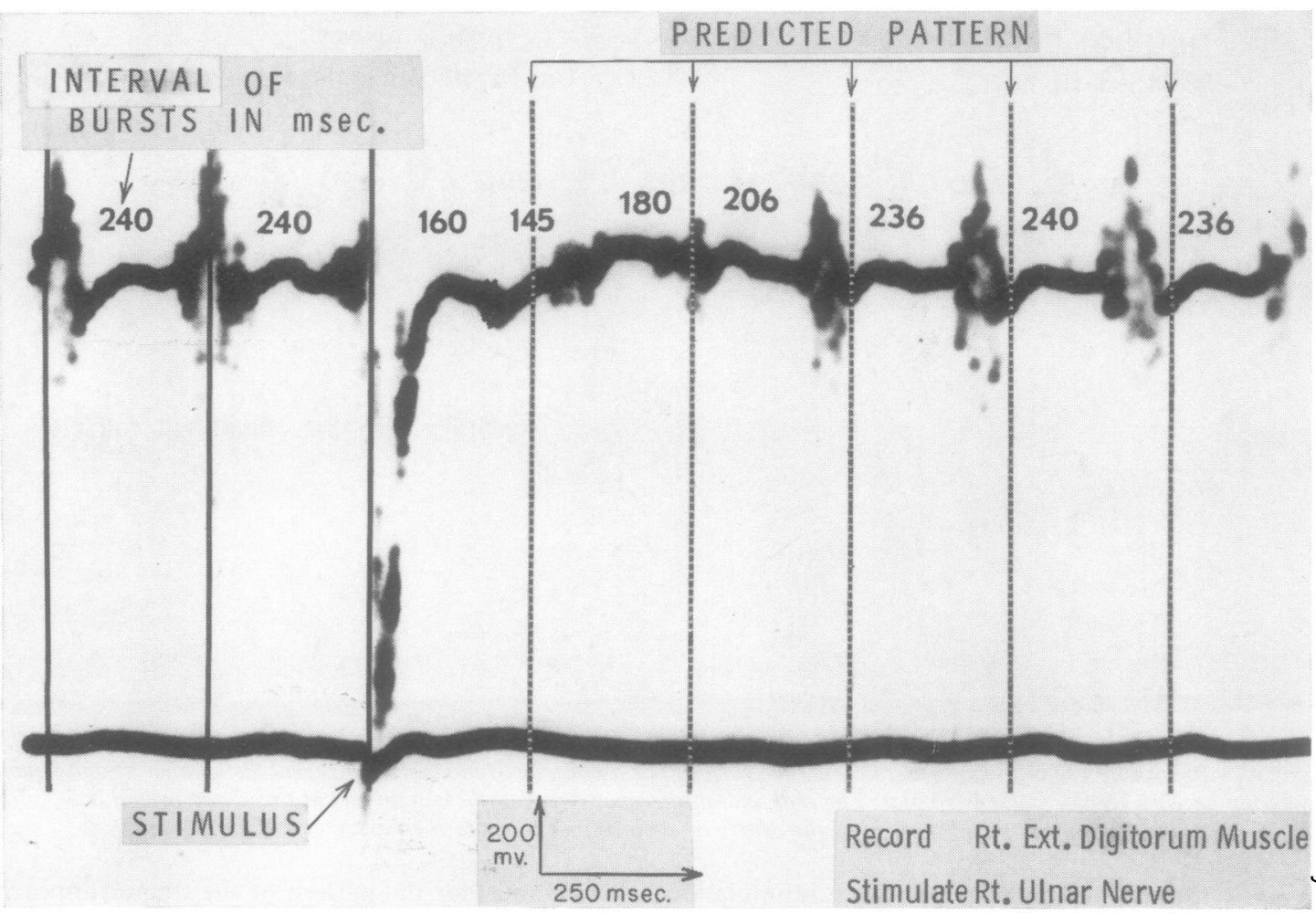

FIG. 2a. Ipsilateral ulnar nerve stimulation showing a dramatic change in the spontaneous tremor bursts after stimulation. The numerals indicate the intervals between the observed tremor bursts. The 'predicted pattern' is the burst pattern thate would have been seen if no stimulation had been given (both the intervals and phase of the tremor bursts would remain? relatively constant). The post-stimulation intervals are significantly reduced from the control of $240 \mathrm{msec}$, after which there is a gradual return to the control interval after four post-stimulation bursts. Although the tremor bursts return to a normal control interval and voltage, they do not return to the 'predicted pattern', since they remain out of phase with the prestimulation bursts. There is a transient decrease in the voltage and number of motor units in the three bursts immediately after the stimulus.

interval occurring immediately after nerve stimulation was interval +1 and subsequent intervals +2 , +3 , etc. The effect of the nerve stimulation was thus averaged for $202 \mathrm{sec}$ periods. In the averaging method as described above, a dramatic effect was noted on the spontaneous tremor burst in the first 750 msec after the nerve stimulation. The interval between the tremor burst in the control period was remarkably constant when the sweeps were averaged (Fig. 4). When $202 \mathrm{sec}$ periods were averaged, a difference of less than $3 \%$ between tremor intervals was found. After averaging these periods, the first tremor interval after ipsilateral ulnar-nerve stimulation was $208 \mathrm{msec}$ when compared with the control tremor interval value of $255 \mathrm{msec}(18 \%$ difference). The change with the ipsilateral median nerve stimulation was from a control of $245 \mathrm{msec}$ to $202 \mathrm{msec}(17 \%$ difference). In the contralateral nerve stimulation experiments the changes were small and unclear. The control intervals of $275 \mathrm{msec}$ were slightly changed

TABLE I

TREMOR OF EXTENSOR DIGITORUM LONGUS

\begin{tabular}{|c|c|c|c|}
\hline & \multirow{2}{*}{$\begin{array}{c}\text { Change in } \\
\text { tremor } \\
\text { interval }\end{array}$} & $\begin{array}{l}20 \text { 2-sec periods } \\
\text { averaged }\end{array}$ & \multirow{2}{*}{$\begin{array}{c}\text { Returned } \\
\text { to predicted } \\
\text { tremor } \\
\text { pattern }\end{array}$} \\
\hline & & $\begin{array}{c}\text { Maximum } \\
\text { difference } \\
\text { between tremor } \\
\text { intervals } \\
(\%)\end{array}$ & \\
\hline $\begin{array}{l}\text { Control tremor } \\
\text { Ipsilateral nerve } \\
\text { stimulation }\end{array}$ & $\begin{array}{l}\text { No change } \\
\text { Short intervals } \\
\text { for } 750-1,000 \\
\text { msec }\end{array}$ & $\begin{array}{r}3 \\
18\end{array}$ & $\begin{array}{l}\text { Yes } \\
\text { No }\end{array}$ \\
\hline $\begin{array}{l}\text { Contralateral nerve } \\
\text { stimulation }\end{array}$ & $\begin{array}{l}\text { Slight shorten- } \\
\text { ing (equivocal) }\end{array}$ & 5 & Yes \\
\hline
\end{tabular}




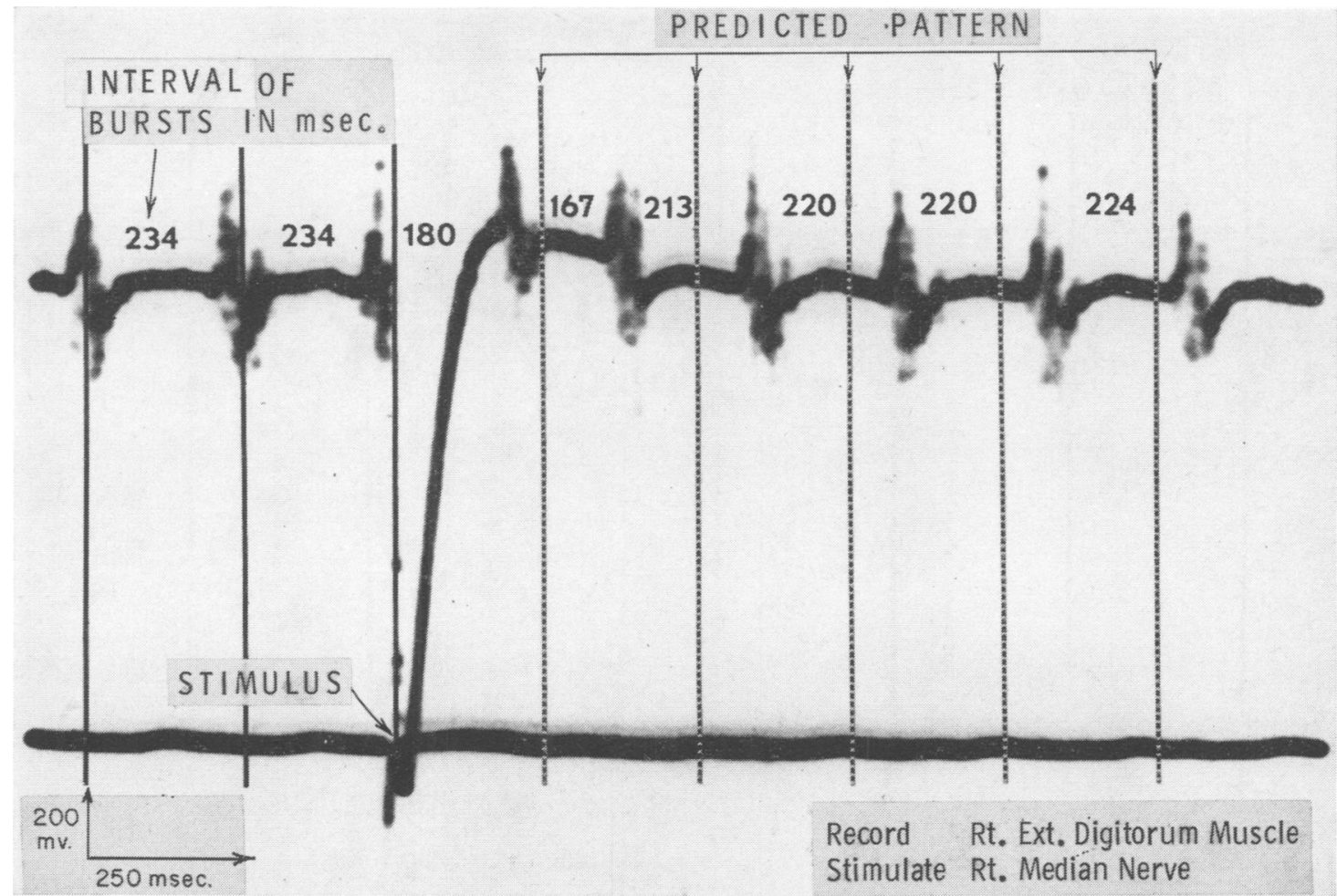

FIG. 2b. Stimulation of ipsilateral median nerve. The tremor has been 'reset' due to a phase change in the tremor bursts, even though the interval has almost returned to that seen before stimulation. There is a gradual return from the first poststimulation interval to the control level. (180 msec, $167 \mathrm{msec}, 213 \mathrm{msec}$, and then $220 \mathrm{msec}$.)

after contralateral ulnar or median nerve stimulation to $260 \mathrm{msec}$ and to $262 \mathrm{msec}$ respectively. This represents a difference of $5 \%$ (Fig. 4).

\section{DISCUSSION}

Previous work on the effect of peripheral nerve stimulation on the spontaneous tremor in the Parkinson patient has been scanty. Liberson (1962) noted a change in the tremor pattern when the ipsilateral arm nerve was stimulated. There was a tendency for the tremor interval immediately after the nerve stimulation to shorten but the exact pattern of change was not reported. Hufschmidt (1962) did similar experiments and reported that the initial tremor burst interval after the nerve stimulation was shortened, but he found that subsequent tremor intervals were all identical with the tremor in the control period. He used this type of data to support his thesis that the genesis of the Parkinsonian tremor is in the spinal cord and not in higher structures. The nerve stimulation, however, affects all levels of the nervous system, and therefore this type of data does not appear to prove the locale of the tremorgenic area, if such a centre exists.

The genesis of the tremor of Parkinsonism has interested many observers in the past. The often quoted experiment by Pollock and Davis (1930) is usually cited to indicate that sensory input from the limb is not necessary for tremor. They cut the posterior roots of a patient with Parkinsonism and did not observe a decrease in the tremor. Such experiments have also been done by Stein and Carpenter (1965) in the monkey after experimental dyskinesia experiments. Again their results indicated that sensory input from the limb is not necessary for maintenance of the tremor. Hoefer and Putman (1940) studied the spontaneous Parkinsonian tremor in man with electromyography. They noted an alternation of the tremor between synergists and antagonists, but also cited examples of asynchronous tremor bursts in the same limb or in the ipsilateral limbs. Jung (1941) noted the difference in tremor frequencies in the same patient in the leg and the arm and felt that the asynchrony of tremor bursts indicated a lack of a central tremorgenic area. He 


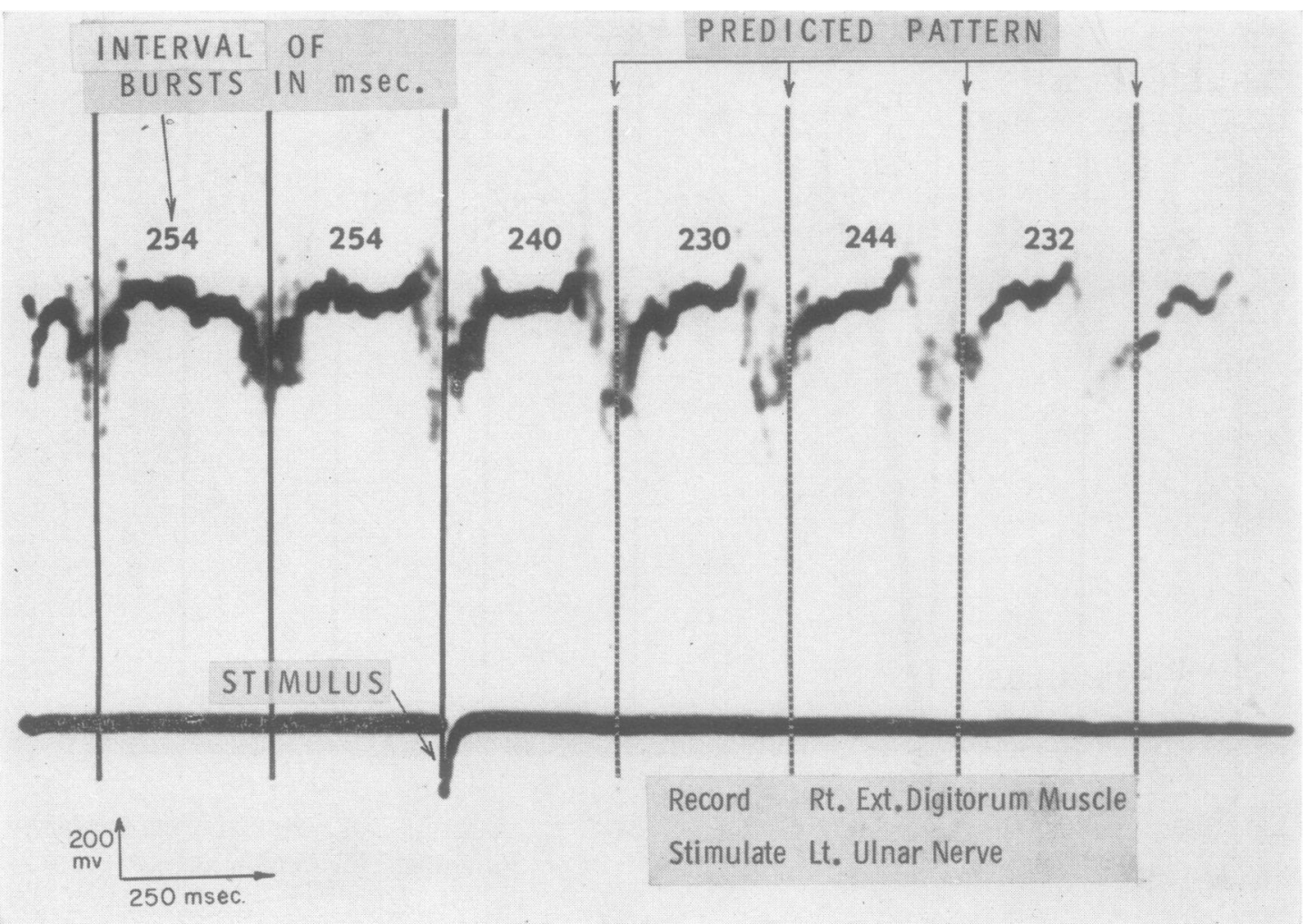

FIG. 3. The contralateral nerve stimulation experiment showed no definite change or a borderline decrease in the tremor interval after nerve stimulation. The figure shows the maximal change noted in the contralateral experiments. A small but definite change is noted in the tremor interval and a slight shift of the phase of the tremor from the predicted tremor pattern. The changes are much less dramatic than those in Figures $2 a$ and $2 b$.

used this data to support his thesis that the tremor was essentially a spinal cord phenomenon.

There have been many studies of the electrical activity of the thalamus in man during operation for dyskinesias. Macroelectrode studies have not shown any correlation between the electromyogram of the contralateral limb and the thalamus. However, intracellular recordings of Cordeau et al. (1960) have shown that in animals with experimental tremor there are rhythmic bursts of single cells in the cerebrum, putamen, globus pallidus, and the ventrolateral thalamus which are synchronous with the electromyogram of the contralateral limb. As the rhythmic single cell activity in these units could be the result of sensory input from the moving contralateral limb, Flaxedil was given, which caused a complete paralysis of the limb by blockade of the neuromuscular junction. The 4 to $5 \mathrm{sec}$ activity in these units persisted. This gave evidence that there is a tremorgenic region in higher structures and that such activity in the thalamus is not due to sensory input. Lamarre and Cordeau (1963) described ventrolateral thalamic unit discharges which were synchronous with the contralateral tremor, but also reported that at times the rhythmic bursts continued in the thalamus after the trenor in the limb stopped.

Jasper and Bertrand (1966) and Albe-Fessard, Guiot, Lamarre, and Arfel (1966) have shown in human Parkinsonism that there are cells in the ventrolateral thalamus which beat synchronously with the tremor electromyogram in the contralateral limb. These experiments were done in man and therefore studies with Flaxedil were not done to confirm the work of Cordeau in animals. Albe-Fessard et al. (1966) noted that rhythmic discharges of 4 to $5 \mathrm{sec}$ activity are seen in the ventrolateral thalamus of normal monkeys during anaesthesia, although they are not seen in the awake monkey. Cordeau did not find 4 to $5 \mathrm{sec}$ activity in the thalamus of normal animals which were given Flaxedil, whereas the 
RT. EXT. DIGITORUM TREMOR

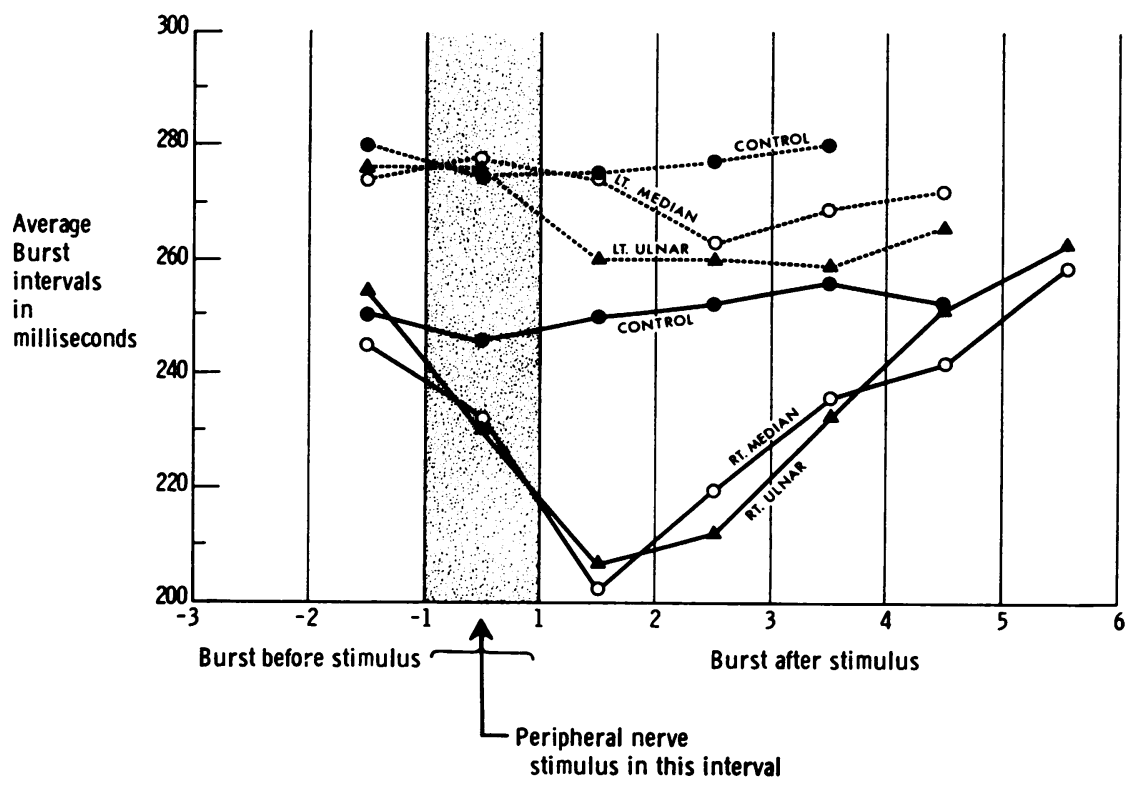

FIG. 4. Summary of the results of the tremor recordings of the right extensor digitorum longus muscle of one patient. Each value shown represents the average value of $202 \mathrm{sec}$ periods analysed in each of the five following categories. See text for explanation. (1) Control. (2) Right ulnar stimulation. (3) Right median nerve stimulation.(4) Left ulnar nerve stimulation. (5) Left median nerve stimulation.

The contralateral experiments (dotted lines) show minimal change in the tremor burst interval, although values up to $5 \%$ difference are noted after contralateral ulnar nerve stimulation.

The ipsilateral experiments (solid lines) show obvious decrease in the values of the tremor intervals after stimulation. The effect of the single supramaximal stimulation to the ipsilateral nerve lasts for three intervals, or about 750 msec.

The control values for the contralateral nerve stimulation experiments were $280 \mathrm{msec}$, whereas the control values for the ipsilateral nerve stimulation experiments (done one hour later) were 250 msec. This difference is due to the spontaneous change seen in these tremors during long observation periods.

animals with the spontaneous tremor did have a $5 \mathrm{sec}$ burst activity in the ventrolateral thalamus during Flaxedil experiments. Although the work cited suggests that the ventrolateral thalamus is intimately related to the spontaneous 4 to $5 \mathrm{sec}$ tremor bursts seen in patients with Parkinsonism, the existence of a single tremorgenic area in the brain has not been established.

In this paper we have emphasized that the spontaneous tremor in patients with Parkinsonism responds to ipsilateral nerve stimulation with a clear and dramatic change both in the interval of the tremor burst and in the phase of the subsequent tremor after the control tremor interval has reasserted itself. The contralateral experiments revealed only a minimal change of questionable significance. The phenomenon described is not a diffuse alerting phenomenon or a non-specific response to pain. The unilateral character of the response would indicate a localized or at least a unilateral sensory-motor interaction occurring somewhere in the nervous system. The exact area involved is not established by this work. Future experiments involving multiple recordings of muscles, electroencephalograms, and intracerebral recordings may determine the localization of the effect we have described.

It is interesting that it took between 750 and 1,000 msec for the control tremor interval to reassert itself after the unilateral ipsilateral nerve stimulation. We have shown that the initial interval between tremor bursts after the nerve stimulation was decreased and then gradually increased back to the control pattern. 
The relatively long period of time for the return to the control tremor interval implies that multiple neurones are involved in the phenomenon.

It was also noted that the number of motor units in the tremor burst after nerve stimulation was decreased and that the voltage was decreased. Hufschmidt (1962) noted this decrease in voltage and number of motor units and suspected that the subsequent decrease in tremor intervals was caused by the change in afferent muscle stimulus firing into the spinal cord. A definite statement concerning the relationship of the interval of the tremor burst and the voltage and number of motor units in previous tremor burst is not possible from our data.

\section{CONCLUSION}

The spontaneous tremor of the extensor digitorum muscle of the patient with Parkinsonism can be modulated and altered by ipsilateral nerve stimulation of the distal median or ulnar nerve. The interval of the post-stimulation tremor bursts was decreased when compared with control values. Contralateral nerve stimulation did not change this pattern in a comparable manner, although there was a slight change in the initial interval. The significance of the phenomena described is not clear. The area of the sensory-motor interaction which modulates the tremor burst interval was not established.

\section{REFERENCES}

Albe-Fessard, D., Guiot, G., Lamarre, Y., and Arfel, G. (1966). Activation of thalamocortical projections related to tremorgenic process, pp. 237-253 in The Thalamus. Edited by D. P. Purpura and M. D. Yahr. Columbia University Press: New York.

Aronson, N. I. (1966). Neurophysiology of tremor. J. Neurosurg., 24, 207-209.

Cordeau, J. P., Gybels, J., Jasper, H., and Poirier, L. J. (1960). Microelectrode studies of unit discharges in sensorimotor cortex. Nerology (Minneap.), 10, 591-600.

Hoefer, P. F. A., and Putnam, T. J. (1940). Action potentials of muscles in rigidity and tremor. Arch. Neurol. Psychiat. (Chic.), 43, 704-725.

Hufschmidt, H. J. (1962). Questions on tremor and ataxia. Electroenceph. clin. Neurophysiol., 22, 114-119.

Jasper, H. H., and Bertrand, G. (1966). Thalamic units involved in somatic sensation and voluntary and involuntary movements in man, pp. 365-390 in The Thalamus. Edited by D. P. Purpura and M. D. Yahr. Columbia University Press: New York.

Jung, R. (1941). Physiologische Untersuchungen uber der Parkinson Tremor und Andere Zitterformen Beim Menschen. $Z$. ges. Neurol. Psychiat., 173, 263-332.

Lamarre, Y., and Cordeau, J. P. (1963). Central unit activity in monkeys with postural tremor. Fed. Proc., 22, 457.

Liberson, W. T. (1962). Monosynaptic reflexes and their clinical significance. Electroenceph. clin. Neurophysiol., 22, 79-89.

Markham, C. H., and Rand, R. W. (1963). Stereotactic surgery in Parkinson's disease. Arch. Neurol. (Chic.) 8, 621-631.

Pollock. L. J., and Davis, L. (1930). Muscle tone in Parkinsonian states Arch. Neurol. Psychiat. (Chic.), 23, 303-319.

Stein, B. M., and Carpenter, M. B. (1965). Effects of dorsal rhizotomy upon subthalamic dyskinesia in the monkey. Arch. Neurol. (Chic.), 13, 567-583. 